Research, part of a Special Feature on Balancing Ecology and Community using Cumulative Effects Models

\title{
Deliberative Democracy, Institution Building, and the Pragmatics of Cumulative Effects Assessment
}

\author{
$\underline{\text { John R. Parkins }}^{1}$
}

\begin{abstract}
Cumulative effects assessment is a process of scientific analysis, social choice, and public policy development, yet the linkages among these domains are often less than transparent. Limits to scientific and technical assessment, issues of power and control of information, and episodic forms of civic engagement represent serious challenges to meaningful understanding of cumulative effects assessment and land-use planning. In articulating these challenges, I draw on case studies from Ontario's Lands for Life and Alberta's Land-use Framework to illustrate current limitations to cumulative effects assessment on public lands in Canada. As a partial remedy for these limitations, insights into a pragmatic approach to impact assessment, in contrast to decisionistic and technocratic approaches, offer a way forward through a more robust integration of scientific information, civic engagement, and public policy development. I also identify a need for longer-standing institutions that are dedicated to regional planning and cumulative effects assessment in Canada.
\end{abstract}

Key Words: case study; environmental sociology; Land-use Framework; Lands for Life; regional planning; social imaginary

\section{INTRODUCTION}

Cumulative effects assessment is entrenched within several levels of government legislation and public policy in Canada. At the federal level, cumulative effects assessment is encoded in the Canadian Environmental Assessment Act of 1992, whereby a comprehensive review requires that every project is assessed in terms of the "environmental effects of the project, including ... any cumulative environmental effects that are likely to result from the project in combination with other projects or activities that have been or will be carried out" (subsection 16.1). This federal legislation is mirrored within many provincial jurisdictions whereby the impact of multiple projects is to be considered within the scope of a project-specific environmental impact assessment. In Alberta, for instance, the Environmental Protection and Enhancement Act of 1993 states that cumulative effects must be considered in the context of regional, temporal, and spatial considerations.
Although the legislation and policy context for cumulative effects assessment in Canada is oriented around a cumulative understanding of projectspecific impacts, there are several clear limitations to this approach. First, thinking cumulatively and regionally does not emerge naturally from a projectbased perspective. Within the conventional assessment framework, cumulative impacts are often described simplistically as additive impacts from multiple projects on indicators such as employment, water use, road use, or pollution output based on existing and proposed projects. Moreover, there is considerable redundancy in cumulative effects assessment if all large-scale project proposals within a region are undertaking somewhat similar assessments of the cumulative impacts. Second, thinking cumulatively in this context does not facilitate broader discussions about regional limits to development and change and the ways in which specific projects and impacts are aligned or misaligned with regional development goals and objectives. 
Because of these shortcomings within Canadian policy and practice, critics such as Duinker and Greig (2006) have made unequivocal claims about the failings of current environmental impact assessment legislation as a tool to address issues of cumulative impacts at a landscape level. These authors define cumulative effects assessment as a component of environmental impact assessment with a focus on valued ecosystem components (VECs) and the cumulative stressors that affect VECs. Stressors are derived from multiple human activities, and any cumulative impact assessment of these stressors would require extensive crosscutting analysis of multiple projects and multiple stressors over time and space.

Although Duinker and Grieg (2006) offer a useful framework for understanding cumulative effects assessment, other authors identify more diverse ways of defining and understanding the process of cumulative effects assessment. According to Smit and Spaling (1995), there are two distinctive approaches to cumulative effects assessment. The first approach, similar to the definition above, sees cumulative effects assessment as a scientific approach to data gathering that is then communicated to land-use planners and decision makers. In this sense, as a source of information that is required for decision making, it is distinct from decision making itself. The second approach draws a much closer link to formal planning activities through the determination of preferences and resource allocations, the identification of social norms, the ranking of alternatives, and an explicit focus on trade-offs among various social objectives. In this way, cumulative effects assessment is closely aligned with land-use planning activities.

With reference to the second definition of cumulative effects assessment, many jurisdictions within Canada are attempting to deal with cumulative effects assessment within the context of land-use planning. This planning approach offers an opportunity to move beyond the limits of projectbased assessment as an assessment of individual projects to cumulative effects assessment as an assessment of regional plans and objectives. This shift is consistent with recent literature on strategic assessment (Noble 2000) and several Canadian initiatives on land-use planning such as the Ontario Lands for Life case and the Alberta Land-use Framework, which I discuss below.

In acknowledging these conceptual advances, there remain several clear challenges in this regional planning approach to cumulative effects assessment that offer a point of focus. These challenges include the limitations of scientific and technical capacities, issues of power and control of information, the limits of our own human imaginations, and a thin veneer of democratic decision making that is often associated with regional planning. Two case studies, in Ontario and Alberta, are provided to illustrate these challenges and identify a pathway forward through institutional development for long-term planning and cumulative effects assessment.

\section{TWO APPROACHES TO CUMULATIVE EFFECTS ASSESSMENT}

In defining three general approaches to impact assessment, Dietz (1987) provides a conceptual framework for my analysis and a starting point to begin examining alternatives to the current projectbased orientation of cumulative effects assessment in Canada. The first two approaches are described as fairly conventional modes of undertaking impact assessment. Described in their idealized form here, i.e., a more extreme characterization, I characterize both the technocratic approach and the decisionistic approach to impact assessment as a cautionary tale of what needs to be avoided in the design of cumulative effects assessment procedures.

\section{Technocratic approach}

There are well-established scientific procedures for land-use planning and cumulative effects assessment within the published literature. Ecologists employ models of ecological change and deal with complex interactions over time between landscape changes, land-use changes, and the interactions of demographic change, climate change, industrial activity, and many other dimensions of the human and natural ecosystem dynamics (Carlson et al. 2010). Within the social sciences, there are similar models of scientific assessment that are based on simulations of consumer behavior or regional economic change (Patriquin and Adamowicz 2008). The extent to which these science-based decision-making approaches dominate the field of cumulative effects assessment and dictate the terms of discussion and debate around critical land use issues is consistent with what Dietz (1987) describes as a technocratic approach to impact assessment. In this approach, technical information is derived from computerbased ecological models or economic models, and 
this information is used as the primary basis for decision making about land uses and cumulative effects assessment. Within this approach to impact assessment, according to Dietz (1987), the political process is subordinated to scientific and technical information. Politics are still present, and stakeholders may be involved in the formulation of scientific models and scenarios, but there are attempts to overcome politics through science by attempting to provide objective observations and guidelines for decision makers that are informed by the scientific method and robust forms of knowledge and prediction.

In this way, where science and technique become dominant in cumulative effects assessment, the tendency is to rely on economic instruments such as cost-benefit analysis or the output of computergenerated future land-use simulations as the basis for public policy decisions. This approach is taken not only because of growing interest in, and capacities of, science-based management systems, but also as a method of getting around entrenched political interests that are considered to be disruptive and counterproductive to the planning process. A result of this approach is the development of technical solutions for land-use planning that are then marshaled through a process of civic engagement to gain acceptance and political legitimacy as a public policy option. With this approach to impact assessment, politics are subordinated to the triumphs of science and technology.

\section{Decisionistic approach}

A very different mode cumulative effects assessment involves the complete reversal of relations between science and politics. Partly because of the recognized limitations of scientific and technical information, planners and policy makers are constantly faced with situations for which scientific information is incomplete and uncertainty and complexity limit the possibilities for clear choices. In this context, dominant political and economic players take hold of a decisionmaking process, and entrenched political and economic interests are in a position to wield considerable influence over land-use plans and decisions. Under these conditions, cumulative effects assessment has less to do with technical and scientific methods and more to do with the maintenance of power and the retrenchment of dominant political and economic interests, which is a negative political space.

Drawing on Dietz's (1987) idea of a decisionistic approach to impact assessment, there is strong emphasis on conventional elite-based political processes and the influence of stakeholders and key interest groups in the decision-making process; in this way, scientific and technical information is subordinated to the political process. Freudenberg and Olsen (1983) offer a classic example of this decisionistic approach in the decision about locating a large-scale industrial development that was more a function of powerful and elite interests than it was a decision based on technical or scientific evidence. Science often remains or masquerades as an important part of the process, but politics come first; key resources, economic interests, and directions for development are decided by key decision makers, and then science and technical information is applied to support these decisions. With a decisionistic approach, there is a focus on the ways in which scientific information is hijacked or sidetracked by political interests or the ways in which science is commandeered in the interests of dominant political or economic interests. The decisionistic approach therefore puts politics first and then goes about marshaling technical information to support a purely political decision.

\section{A THIRD WAY: PRAGMATIC APPROACH}

Obviously both of these approaches to decision making within the context of cumulative effects assessment are not ideal. The technocratic approach places too much emphasis on the capabilities of science to provide optimal, sustainable, and socially acceptable solutions to land-use planning issues. The decisionistic approach places too much emphasis on politics of the status quo and the use of technical information in support of dominant political, economic, or ideological interests. As a third way, a way of avoiding the extremes of these other positions, Dietz (1987) proposes a more pragmatic alternative to impact assessment. He refers to this third way as a pragmatistic mode of decision making, but for simplicity, I use the term pragmatic.

At the core of this pragmatic approach is a focus on democracy, and on the notion of deliberative democracy, in particular (Parkins and Mitchell 2005). As a counterpart to electoral or representative 
democracy, deliberative democracy is based on criticisms of more episodic forms of democratic participation in which involvement is limited to voting or in which public knowledge and public debate are limited to little more than sound-bites from interest groups and popularity contests among the political leadership. In contrast to this episodic and thin version of democracy, deliberative democracy is concerned with more extensive forms of "debate and discussion aimed at producing reasonable, well-informed opinion in which participants are willing to revise preferences in light of discussion, new information, and claims made by fellow participants" (Chambers 2003:309). Since the early 1990s, deliberative democracy has flourished into an influential body of both theory (Bohman and Rehg 1997, Elster 1998, Dryzek 2000) and practice through grassroots networks and organizations such as America Speaks and the Deliberative Democracy Consortium. These organizations promote civic engagement in ways that are consistent with principles of deliberative democracy.

As a remedy for the limits of the technocratic and decisionistic approaches to impact assessment, Dietz (1987) draws on this tradition of deliberative democracy to find ways to move beyond polarized and one-sided positions. He calls for a more pragmatic approach to impact assessment that is situated at a distance from technocratic and decisionistic approaches. The pragmatic approach offers legitimacy to scientific and technical information as an important component of decision making, but instead of privileging science over values, it calls for openness and equality of information that is based on multiple sources and modes of information for public discussion, debate, and decision making. In this way, the pragmatic approach also stands in contrast with the backroom politics of the decisionistic approach. Out of these procedural elements, the integration of scientific information and public values is intended to emerge under basic democratic principles of openness, transparency, and inclusivity, as well as full recognition of the diversity of public values and the complexity and uncertainty of scientific information.

In promoting the pragmatic approach, Dietz (1987) offers several key arguments about why the technocratic approach, in particular, is antidemocratic in ways that are not immediately apparent. First, much of the expertise that is required for ecological and economic modeling is held by a small group of experts, so when it comes to public policy-making processes, this black box of technology stands in opposition to the democratic norms of openness, transparency, and accountability. This is not simply a problem of translating and communicating scientific information to the general public, however, but a more serious lack of public understanding, public dialogue, and debate about modeling assumptions and the strengths and weaknesses of given scientific approaches to decision making. These important scientific questions are largely closed off to public discourse and democratic decision making and therefore limit the possibilities for a pragmatic approach to impact assessment.

Second, because of the high costs involved in developing scientific models for cumulative effects assessment, much of the science that goes into this work is held within industry and government agencies. The privileging of this scientific knowledge and the dominant role of government and industry in this assessment process results in a political dynamic that is often tilted toward industrial and government science as the authority regarding expected cumulative impacts within a planning region. In other words, scientific "legitimacy is a source of power for those whose position on a policy is supported by the technical analysis" (Dietz 1987:59). These points raise rather serious questions about the possibilities for a healthy and genuinely democratic moment for decision making to emerge in this context. To put the point more bluntly, as big science enters the sphere of public discussion and debate, the possibilities for meaningful civic engagement and democratic decision making are often compromised.

In addition to these issues of power and politics in the science of cumulative effects assessment, another aspect of democratic life that extends beyond Dietz's (1987) framework seems quite germane to this discussion. This issue involves aspects of the human condition, and the human imagination in particular, that can limit the possibilities for meaningful public interaction and democratic decision making. An expression of this concern is articulated within several strands of scholarship, perhaps most notably in the influential work of Castoriadis (1987) and his notion of imaginary as the unceasing and undermined creation of what we understand as reality through social, psychological, and historical processes. The imaginary in this sense offers a way for society to 
provide answers to the big questions of life. Who are we in a collective sense? What do we want? What do we desire? With deep insight into the ways in which a social imaginary pervades our so-called rational modern world, Castoriadis (1987:156) states that despite our sense of rational decision making as an undergirding force in modern life, "the life of the modern world is just as dependent on the imaginary as any archaic or historical culture." Drawing on these ideas, Leahy et al. (2010) explore contemporary resistance to social change in the face of climate change as a function of the social imaginary. In their words, "this mode of thought is based on a set of fictions, which become real if society operates by them. People forget human beings have imagined them, and often feel powerless to intervene" (Leahy et al. 2010:864).

The philosopher Charles Taylor has also focused part of his scholarly work on the limits of human imagination and creativity. In an earlier formulation of these ideas, Taylor points to a tendency for human civilization to be guided by a set of principles or maxims around economic prosperity and economic growth that can eclipse important questions of justice, equity, and higher ideals of the good life that we all share. Taylor (1991) points to a general fear that things that ought to be determined by other criteria will be decided in terms of efficiency or costbenefit analysis and that the independent ends that ought to be guiding our lives will be eclipsed by the demand to maximize output. There are lots of things one can point to that give substance to this worry, for instance, the ways that demands of economic growth are used to justify very unequal distributions of wealth and income or the way these demands make us insensitive to the needs of the environment, even to the point of potential disaster (Taylor 1991).

In a more recent discussion of the social imaginary, Taylor (2007) articulates a more subtle sense in which our imaginations of possibility are limited by the social context in which we find ourselves. In this idea of the social imaginary, we recognize that society is set within a structure of norms and expectations and have a sense of the limitations of our own economic and social context. These limits appear to be entirely self-imposed, i.e., a normative structure, and they are also difficult to escape through any conventional sense of discursive engagement and social learning. Processes of social change are therefore a long-term proposition and cannot be addressed adequately through episodic or short-term bursts of visioning and planning.
The link from social imaginary to cumulative effects assessment turns on the idea that even when we have opportunities to constructively engage in planning processes, we are not only limited by technical capacity, but by our human imagination and a general ethos of our age that brackets our sense of what is possible. This point is taken up by other authors who have noted that there are limitations in terms of information, creativity, and imagination to understand an expanded range of land-use options and cumulative effects (Smith 2003). Yet there remains very little recognition of these issues within the current practice of cumulative effects assessment.

A constrained imagination as to what is possible can be highly problematic when it comes to issues of social choice within a planning context. These constraints are reflected in technical procedures that are used by economists, as well as more processoriented activities for civic engagement and democratic decision making. Social choice is also thought to be constrained by geo-economic location such as a forestry town where individual worldviews and dispositions are conditioned by economic and social dependencies on local industrial actors (Davidson et al. 2003).

In summary, there are obvious as well as not so obvious ways in which our current approaches to cumulative effects assessment are constrained by overly technocratic or decisionistic approaches to decision making. Moreover, in our attempts to remedy this situation with a pragmatic approach, there remain considerable challenges in achieving more democratic decision making to overcome the limits of our social milieu, normative structures, and ways of imagining our world and our chosen livelihoods. To illustrate the dimensions of these constraints in a real world setting, I examine two case studies in which land-use planning and cumulative effects assessment were points of focus. The Ontario example took place in the late 1990s and offers an opportunity to reflect and learn. The Alberta example was unfolding during my analysis of this topic; therefore, its insights are more tentative and emergent. Evidence for both cases was drawn from secondary data in the form of published academic sources, policy documents, government reports, and a measure of my personal involvement and reflection in the Alberta case. These cases involved broad and diverse settings, allowing a focus on issues of political process, civic engagement, and the use of scientific information 
in ways that are connected to the conceptual framework presented here. Following these descriptive accounts, I explore ways of cutting through these deep challenges by building institutions for cumulative effects assessment.

\section{ONTARIO LANDS FOR LIFE}

The Lands for Life planning process in Ontario was designed to provide a long-term solution to the allocation of resource use and protected areas in the near-north regions of the province. Throughout the 1980s and 1990s, the region witnessed growing conflict between industrial uses such as mining and forestry and growing demands to set aside areas for preservation. A stated goal of the Lands for Life planning process was to deal with this conflict between exploitation and preservation in the region. In 1997, the Government of Ontario initiated roundtable processes to facilitate public discussion in three planning regions: Boreal West, Boreal East, and Great Lakes-St. Lawrence. Round-table participants represented a range of interests from industry to environmental organizations, and the breadth of stakeholder representation was considered by some analysts to be relatively balanced (Cartwright 2003:122). A controversial aspect of these round-table meetings, however, was that only residents from the regions were permitted to sit on the regional round tables. In particular, there were no plans for community meetings or roundtable representation from the densely populated cities of southern Ontario (Rodgers 2001).

After considerable protest from the public and a statement from the Environmental Commissioner of Ontario, a series of public meetings were hastily scheduled for four southern Ontario cities. On short notice, more than 600 people attended these meetings in southern Ontario, and a series of followup round-table meetings resulted in considerable attention from the largely urban population. As an example, in response to preliminary recommendations for protected areas in the north, the government received 6820 submissions from the public, many of which were critical of the recommendations. By the end of the planning process, 190 public meetings were attended by more than 15,000 people, and the government received more than 40,000 public responses by mail (Rodgers 2001).

After this first set of recommendations was released, there was strong public reaction about the minimal extent of proposed new protected areas. Protest came not only from environmental organizations but also from the general public (Cartwright 2003). This protest resulted in a subsequent series of private meetings between the provincial government, key environmental organizations, and industry leaders that resulted in a new framework for land use in the north and significantly more land set aside in protected areas. The Forest Accord (Government of Ontario 1999) set aside new parks and conservation areas totaling 2.4 million hectares, and the forest industry received assurances that future fiber requirements would be achieved through more intensive forest management. On one level, the Ontario Lands for Life process was a success in that many groups and individuals were engaged in the process through public meetings and individual submissions. The Forest Accord also appeared to strike a balance between environmental and industrial interests. In spite of extensive efforts at civic engagement and a new deal in the Forest Accord, there remained a significant amount of public criticism, particularly in southern Ontario, regarding the Lands for Life process (Kidd and Sinclair 2007; Michael McDonnell, "Behind the scenes of Lands for Life," Toronto Star 2 April 1999, $1)$.

Two limitations to the Ontario process are notable. First, public participation from those not living within the planning region was an afterthought. Only after serious protest from the general public did the planning process open up to residents in southern Ontario. Although many jurisdictions in Canada allow only those directly affected by a development to have standing within an environmental impact assessment, for a long time in Canada there have been strong philosophical arguments in favor of broad-based civic engagement in public land management (Behan 1966). This issue of public participation by locals and non-locals, directly affected and not directly affected, continues to plague processes of regional planning and is indicative of a key challenge in cumulative effects assessment as well. Who is being affected, how are they affected, and how do we decide the parameters for civic engagement?

Second, considerable dissatisfaction with the outcome of the round-table process and the public meetings across Ontario resulted in a backroom deal, The Forest Accord (Government of Ontario 1999). As a template for land use in the near-north, this deal is both an outcome of the round-table 
process and the subsequent public protest, but also an indicator of failed civic engagement. Clearly the process of extensive public meetings and discussions did not result in a set of recommendations that the public could recognize as its own, or as an acceptable compromise or consensus of competing public interests. In this sense, in spite of the large-scale investment in civic engagement, a final decision about land use was made outside of the democratic process, using more conventional backroom politics.

\section{ALBERTA LAND-USE FRAMEWORK}

The Land-use Framework in Alberta was officially launched in December 2008 with seven strategies for land-use planning in the province (Government of Alberta 2008). These strategies include: (1) landuse planning in seven regions, the first two of which were underway in 2009; (2) the creation of a landuse secretariat and a regional advisory council for each planning region; (3) cumulative effects assessment to manage development impacts on land, air, and water; (4) the development of strategies for conservation and stewardship on public and private lands; (5) the efficient use of land; (6) the establishment of monitoring and knowledge systems to improve decision making; and (7) the involvement of Aboriginal people in land-use planning. This document and the accompanying legislation that was passed in June 2009 provided a basis for undertaking cumulative effects assessment within the context of regional land-use planning in Alberta. According to the Alberta Land Stewardship Act (Government of Alberta 2009a:5), land-use planning is intended "to create legislation and policy that enable sustainable development by taking account of and responding to the cumulative effect of human endeavor and other events."

At the heart of the planning process in Alberta is the regional advisory council (RAC). The mandate of this council for the Lower Athabasca Regional Plan is to "bring local insight and perspectives on present and future land-use activities and challenges in the region" (Government of Alberta 2009b:4). This Lower Athabasca region is the high-profile oil sands region of northeastern Alberta and was the first landuse plan to be developed under the new Land-use Framework. Based on the terms of reference for this planning region, the influence of the RAC is extensive and central to the development of a regional plan (Government of Alberta 2009b). The
RAC is involved in all facets of the planning process, including conceptualizing the region in broad terms and providing advice on what the region should look like and how activities should be planned. The RAC is also the point of contact for information from the scientific and technical community through computer-based modeling projections and policy advice from government officials. Taking all of this information into consideration, the RAC is expected to address complex questions about land-use alternatives for the region and then provide considered advice to government about land-use planning for the region.

The RAC for the Lower Athabasca Regional Plan comprised 17 key stakeholders from the region chaired by the Assistant Deputy Minister for the Oil Sands Secretariat, a high-level government appointment. During the planning process, the chair of the Council also held a position as vice-president of Suncor Energy, a leading oil sands development firm in Alberta. Other members of the Council included elected municipal representatives, industry representatives, independent consultants, Aboriginal representatives, and representatives from several environment-oriented groups such as Ducks Unlimited.

In addition to public input through the RAC, the public was given opportunities to provide input through a series of open-house sessions. For instance, in the Lower Athabasca Region, 13 openhouse events took place during 2009 in association with the regional planning process. It is not clear from the terms of reference, however, exactly how the input from these sessions makes its way to the RAC and eventually into the final regional plan. It is also not clear to what extent the public information sessions were intended to facilitate the development of land-use plans as opposed to comment on draft plans as they are developed by government officials. One set of insights into this issue comes from the terms of reference for the regional plan, which states that "public, stakeholder and Aboriginal consultations on the draft Vision, Outcomes and Objectives will be held, using the Alberta government's consultation processes" (Government of Alberta $2009 b: 20)$. What is clear from these documents, however, is that the RAC plays a central role in regional planning.

An early concern in the Alberta case was the structure and composition of this small, influential group of individuals who served on the RAC. The 
apparent conflicts of interests in having an RAC chair that was also employed by big oil did not go unnoticed by local public intellectuals (e.g., Sheila Pratt, "Stelmach's political judgment lacking in civil service appointment," Edmonton Journal 20 August 2007, A:18). Moreover, the RAC was invited by the land-use secretariat to consider the impact of three economic development scenarios for the region. These scenarios were narrowly defined in terms of three levels of oil sands production (low, medium, and high), for which the lowest level of production was 2 million barrels/day (approximately status quo) and the highest level of production was 6 million barrels/day. Unsurprisingly, when the RAC released its recommendations to the Government of Alberta regarding land-use planning in the Lower Athabasca Region, the first objective in the document was to ensure that the economic potential of the oil sands is optimized (Lower Athabasca Regional Advisory Council 2010).

\section{INSTITUTION BUILDING FOR PRAGMATIC CUMULATIVE EFFECTS ASSESSMENT}

These two case studies are indicative of the challenges in building robust democratic frameworks for public policy development. In the Alberta case, there were clear attempts to integrate scientific approaches to decision making in terms of ecological and economic modeling activities that contributed to RAC deliberations. Yet it remains unclear as to how the scenarios for economic development in the Lower Athabasca Region were defined at the outset and what possibilities existed for public influence over the development of these scenarios. With reference to the conceptual framework defined earlier, the limits of human imagination were also in plain view, as illustrated by three future economic development scenarios centered on a single variable: different levels of oil sands production. To paraphrase from Taylor (1991), our collective imaginations of possibility are limited by the social context in which we find ourselves, and these limits are clearly evident in the outcome of such visioning and planning activity within the Lower Athabasca Region.

In examining the democratic dimensions of the Alberta case study in comparison to the Ontario case, a key limitation involves a focus on voluntary and small-group designs for public participation. This form of civic engagement is not well suited to reach beyond conventional interest-based politics and is therefore at risk of capture by local political and economic elites. The planning process in Alberta also provided virtually no opportunity for public input from outside the planning region, particularly the urban areas where more than $80 \%$ of the population resides. Tools for civic engagement in Alberta were designed instead for efficiency and expediency to move through a planning process in a timely and cost-effective manner.

In the Ontario case, there were clear attempts to integrate public participation and public values into the planning process. Ontario undertook extensive and time-consuming processes of public engagement in which thousands of people were actively involved in meetings and in submitting ideas to the planning process. What was missing in the process, however, was a sense of inclusion from the start for citizens in southern Ontario. More importantly, the extensive public engagement that did eventually take place in Ontario did not result in a set of government recommendations that were considered to be legitimate by the people of Ontario. Therefore, at the end of the process, people remained dissatisfied, and a backroom deal between industry, environmental groups, and government was required to reach a compromise.

More sympathetic observers of land-use planning in places like Alberta and Ontario might argue that the development of the Land-use Framework or the Lands for Life process were attempts to implement a pragmatic approach that balances scientific information and public values. These same observers might argue that the problem with cumulative effects assessment is that an ideal process or procedure is not easily achieved, and any good-intentioned process can be derailed easily by scientific complexity, uncertainty, or the relentless influence of dominant stakeholders and special interests. These sympathetic observers may be right. It is certainly possible to view these examples of cumulative effects assessment as well-intentioned exercises in pragmatic decision making and public policy development. What is not clear, however, is the extent to which tinkering with these current techniques and procedures will help us move toward a more pragmatic ideal in a meaningful way.

One way to move beyond this impasse is to begin thinking about cumulative effects assessment and land-use planning as a longer-term endeavor. 
Current institutional arrangements are often quite temporary, and in recent decades, governments have lost even more of their capacity to undertake landuse planning activates because of cutbacks and a general ideological orientation toward laissez-faire capitalism (Parkins 2006). To reverse this trend, if we can move away from an episodic, project-based approach to cumulative effects assessment, a longer-term institutional approach to assessment can result in many positive steps toward the pragmatic ideals. These include a focus on longterm investment in the science and technology of cumulative effects assessment, with attention to current data gaps and the development of specific forms of scientific information to aid ongoing cumulative effects assessment. Interdepartmental cooperation, data sharing, and the construction of more robust monitoring systems are part of capacity building in this regard.

Another positive step extends beyond these opportunities for long-term research and technical improvements and involves the development of institutions and procedures for civic engagement. Deliberative democracy involves attention to issues of power and control, the inclusiveness of decisionmaking processes, transparency, accountability, and many other challenging aspects of civic democratic decision making. Yet we continue to give little attention to this highly complex and important component of cumulative effects assessment. Given the number of times we have failed to undertake civic engagement processes in ways that are deeply transformative and deeply satisfying for citizens and for governments, it is surprising that our investments in these issues do not equal or surpass our investments in more technical and scientific questions of cumulative effects assessment. Building long-term institutions and investing in these ways will be an important step forward in the improvement of cumulative effects assessment in Canada.

\section{CONCLUSIONS}

There is a growing trend within several Canadian jurisdictions toward the integration of cumulative effects assessment and land-use planning. This trend is reflected in processes such as the Land-use Framework in Alberta and Lands for Life in Ontario. Although this linkage between land-use planning and cumulative effects assessment is a positive trend, there are pitfalls in these planning processes that are exemplified by technocratic and decisionistic approaches to decision making. Heavy investments are made in scientific assessment and modeling systems, as exemplified by the Alberta case study, and heavy investments are also made in public participation and the elicitation of public values regarding land use, as exemplified by the Ontario case study. However, these short-term bursts of activity and short-lived organizational commitments continue to come up short in meeting the growing demands and expectations for land-use planning and cumulative effects assessment in Canada. As a remedy, I have offered some justification for investment in longer-term planning processes and institutions that are dedicated to the science and practice of planning. Such institutional developments will not only foster investment in areas of science and technology for land-use planning, they will also foster investment in the democratic requirements of land-use planning that include robust forms of social learning, public discussion, debate, and transparent decision making. Toward this end, a pragmatic approach to cumulative effects assessment provides something of a roadmap for future thinking, institution building, and public investment.

Responses to this article can be read online at: http://www.ecologyandsociety.org/voll6/iss3/art20/ responses/

\section{Acknowledgments:}

I thank the anonymous reviewers for comments and contributions that helped to improve the structure and content of this paper.

\section{LITERATURE CITED}

Behan, R. 1966. The myth of the omnipotent forester. Journal of Forestry 64(6):398-407.

Bohman, J., and W. Rehg, editors. 1997. Deliberative democracy: essays on reason and politics. MIT Press, Cambridge, Massachusetts, USA.

Carlson, M., T. Antoniuka, D. Farr, S. Francis, K. Manuel, J. Nishi, B. Stelfox, M. Sutherland, C. 
Yarmoloy, C. Aumann, and D. Pan. 2010. Informing regional planning in Alberta's oilsands region with a land-use simulation model. In D. A. Swayne, W. Yang, A. A. Voinov, A. Rizzoli, and T. Filatova, editors. 2010 International Congress on Environmental Modelling and Software (Ottawa, 2010). International Congress on Environmental Modelling and Software. [online] URL: http://www .iemss.org/iemss 2010/index.php?n=Main.Proceedings and http://www.alces.ca/publications/download/83/ Informing\%20Regional\%20Planning\%20in\%20Alberta's\% 200ilsands.pdf.

Cartwright, J. 2003. Environmental groups, Ontario's Lands for Life process and the Forest Accord. Environmental Politics 12(2):115-132. htt p://dx.doi.org/10.1080/09644010412331308214b

Castoriadis, C. 1987. The imaginary institution of society. Translated by Kathleen Blamey. Polity Press, Cambridge, UK.

Chambers, S. 2003. Deliberative democratic theory. Annual Review of Political Science 6:307-326. http ://dx.doi.org/10.1146/annurev.polisci.6.121901.085538

Davidson, D. J., T. Williamson, and J. R. Parkins. 2003. Understanding climate change risk and vulnerability in northern forest-based communities. Canadian Journal of Forest Research 33 (11):2252-2261. http://dx.doi.org/10.1139/x03-138

Dietz, T. 1987. Theory and method in social impact assessment. Sociological Inquiry 57(1):54-69. http: //dx.doi.org/10.1111/j.1475-682X.1987.tb01180.x

Dryzek, J. S. 2000. Deliberative democracy and beyond: liberals, critics, contestations. Oxford University Press, Oxford, UK.

Duinker, P. N., and L. A. Greig. 2006. The impotence of cumulative effects assessment in Canada: ailments and ideas for redeployment. Environmental Management 37(2):153-161. http:// dx.doi.org/10.1007/s00267-004-0240-5

Elster, J., editor. 1998. Deliberative democracy. Cambridge University Press, Cambridge, UK. http: //dx.doi.org/10.1111/j.1478-9302.2010.00216.x
Freudenberg, W. R., and D. Olsen. 1983. Public interest and political abuse: public participation in social impact assessment. Journal of the Community Development Society 14(2):67-82.

Government of Alberta. 2008. Land-use framework. Alberta Queen's Printer, Edmonton, Canada. [online] URL: https://landuse.alberta.ca/Documents/ LUF\% 20Land-use\%20Framework\%20Report-2008-12. pdf.

Government of Alberta. 2009a. Bill 36: Alberta Land Stewardship Act. The Legislative Assembly of Alberta. Alberta Queen's Printer, Edmonton, Canada. [online] URL: http://www.qp.alberta.ca/do cuments/Acts/A26P8.pdf.

Government of Alberta 2009b. Terms of reference for developing the Lower Athabasca regional plan. Alberta Queen's Printer, Edmonton, Canada. [online] URL: http://www.ceaa.gc.ca/050/documen ts/45582/45582E.pdf.

Government of Ontario. 1999. 1999 Ontario Forest Accord: a foundation for progress. Queen's Printer for Ontario, Toronto, Canada. [online] URL: http:// www.mnr.gov.on.ca/stdprodconsume/groups/lr / @mnr/@lueps/documents/document/mnr e001782. pdf.

Kidd, S., and J. A. Sinclair. 2007. The urban public and forest land-use planning: tapping into the majority. The Forestry Chronicle 83(2):221-230.

Leahy, T., V. Bowden, and S. Threadgold. 2010. Stumbling towards collapse: coming to terms with the climate crisis. Environmental Politics 19 (6):851-868.

Lower Athabasca Regional Advisory Council. 2010. Advice to the Government of Alberta regarding a vision for the Lower Athabasca region. Lower Athabasca Regional Advisory Council, Edmonton, Canada. [online] URL: http://www.ceaa. gc.ca/050/documents/45413/45413E.pdf.

Noble, B. F. 2000. Strategic environmental assessment: What is it? \& What makes it strategic? Journal of Environmental Assessment Policy and Management 2(2):203-224. http://dx.doi.org/10.1142/ $\underline{\mathrm{S} 146433320000014 \mathrm{X}}$ 
Parkins, J. R. 2006. De-centering environmental governance: a short history and analysis of democratic processes in the forest sector of Alberta, Canada. Policy Sciences 39(2):183-202. http://dx.d oi.org/10.1007/s11077-006-9015-6

Parkins, J. R., and R. E. Mitchell. 2005. Public participation as public debate: a deliberative turn in natural resource management. Society and Natural Resources 18(6):529-540. http://dx.doi.org/10.1080 /08941920590947977

Patriquin, M. N., and W. L. Adamowicz. 2008. Socioeconomic approaches to integrated land management decisions in the Foothills Model Forest and beyond. Pages 42-45 in B. McAfee and C. Malouin. Implementing ecosystem-based management in Canada's forests: a science-policy dialogue. Natural Resources Canada, Ottawa, Canada. [online] URL: http://dsp-psd.pwgsc.gc.ca/collectio n 2008/nrcan/Fo4-21-2008E.pdf.

Rodgers, G. 2001. The evolution of Ontario's Living Legacy. Queen's Printer for Ontario, Toronto, Canada.

Smit, B., and H. Spaling. 1995. Methods for cumulative effects assessment. Environmental Impact Assessment Review 15(1):81-106. http://dx. doi.org/10.1016/0195-9255(94)00027-X

Smith, G. 2003. Deliberative democracy and the environment. Routledge, London, UK.

Taylor, C. 1991. The ethics of authenticity. CBC Massey Lectures. Canadian Broadcasting Corporation, Toronto, Canada.

Taylor, C. 2007. A secular age. Belknap Press of Harvard University Press, Cambridge, Massachusetts, USA. http://dx.doi.org/10.1111/j.1468-0025.2010.01615. 